\title{
Exogenous SDF-1 $\alpha$ Protects Human Myocardium from Hypoxia-Reoxygenation Injury via CXCR4
}

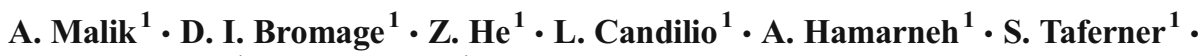 \\ S. M. Davidson ${ }^{1} \cdot$ D. M. Yellon ${ }^{1}$
}

Published online: 20 October 2015

(C) The Author(s) 2015. This article is published with open access at Springerlink.com

Keywords SDF-1 $\alpha$ - Stromal derived factor · CXCR4 .

Ischaemia-reperfusion injury $\cdot$ Cardioprotection

\section{Introduction}

ST-segment elevation myocardial infarction (STEMI) is a consequence of atherosclerotic plaque rupture and thrombotic occlusion of the coronary artery causing downstream ischaemia and, eventually, cell death. The most effective therapeutic strategy for STEMI is timely reperfusion by primary percutaneous coronary intervention (PPCI). Such reperfusion is a prerequisite for myocardial salvage, leading to smaller infarct sizes and improved clinical outcomes [1, 2]. However, reperfusion can itself inflict further injury, termed ischaemia-reperfusion injury (IRI). Despite PPCI, a recent study found 30-day, 1-year, and 5 -year mortality following STEMI to be $7.9 \%, 11.4 \%$, and $23.3 \%$, respectively [3]. Consequently, novel strategies to mitigate the deleterious effects of IRI are paramount.

Stromal derived factor- $1 \alpha$ (SDF-1 $\alpha$ or CXCL12) is a chemokine that has demonstrated cardioprotective activity in mice [4]. We recently demonstrated that exogenous SDF- $1 \alpha$ improved functional recovery of ex vivo rat cardiac papillary muscle subjected to hypoxia and reoxygenation (simulated IRI) [5]. This effect was abrogated by pre-treatment with

A. Malik and D. I. Bromage contributed equally to this work and are joint first authors.

D. M. Yellon

d.yellon@ucl.ac.uk

1 The Hatter Cardiovascular Institute, University College London, 67 Chenies Mews, London WC1E 6HX, UK
AMD3100, a highly specific antagonist of the SDF- $1 \alpha$ receptor, CXCR4.

However, it is not known whether SDF- $1 \alpha$ can similarly protect human heart tissue and whether any such protection is afforded via CXCR4. We address this question using isolated human atrial trabeculae subjected to simulated IRI.

\section{Methods}

\section{Human Atrial Trabeculae Hypoxia-Reoxygenation Experiments}

The study received Local Research Ethics Committee approval and was carried out in accordance with the University College London Hospitals NHS Trust guidelines. A right atrial appendage sample was harvested from 47 patients with chronic stable angina undergoing cannulation for cardiopulmonary bypass for CABG. All patients were aged 18-80 years and there were no significant differences in their baseline characteristics (see Table 1). Patients with diabetes, impaired renal or ventricular function, dilated left atria, unstable angina, or a history of arrhythmias or on rhythm stabilising medications were excluded.

Trabeculae were randomly allocated to [1] control $(n=11)$, [2] hypoxic preconditioning $(n=10)$, [3] SDF-1 $\alpha$ pre-treatment $(n=11)$, [4] AMD3100 + SDF-1 $\alpha$ pre-treatment $(n=10)$, and [5] AMD3100 pre-treatment $(n=5)$. Two separate trabeculae were collected for immunofluorescent staining. The sample was placed in ice-cold buffer prior to careful dissection of the trabeculae. Isolated trabeculae $(\leq 1.2 \mathrm{~mm}$ in diameter and $\geq 2.0 \mathrm{~mm}$ in length) were suspended in a heated $\left(37^{\circ} \mathrm{C}\right)$ organ bath with one end connected to a force transducer. Samples were superfused with oxygenated modified Tyrode's buffer $\left(95 \% \mathrm{O}_{2} / 5 \% \mathrm{CO}_{2}\right)$ at $37 \pm 0.5{ }^{\circ} \mathrm{C}$ and 
Table 1 Patient baseline characteristics

\begin{tabular}{|c|c|c|c|c|c|}
\hline & $\begin{array}{l}\text { Control } \\
(n=11)\end{array}$ & $\begin{array}{l}\text { Hypoxic preconditioning } \\
(n=10)\end{array}$ & $\begin{array}{l}\text { SDF-1 } 1 \alpha \\
(n=11)\end{array}$ & $\begin{array}{l}\text { SDF-1 } 1 \alpha+\text { AMD } 3100 \\
(n=10)\end{array}$ & $\begin{array}{l}\text { AMD3100 } \\
(n=5)\end{array}$ \\
\hline Mean age (years) & 61 & 64.8 & 64.6 & 63.4 & 61.6 \\
\hline Gender (male) & $9(82 \%)$ & $10(100 \%)$ & $10(91 \%)$ & $7(70 \%)$ & $4(80 \%)$ \\
\hline Good LV (>50 \%) & $11(100 \%)$ & $10(100 \%)$ & $11(100 \%)$ & $10(100 \%)$ & $5(100 \%)$ \\
\hline $\mathrm{eGFR}>55 \mathrm{~mL} / \mathrm{min}$ & $11(100 \%)$ & $10(100 \%)$ & $11(100 \%)$ & $10(100 \%)$ & $5(100 \%)$ \\
\hline \multicolumn{6}{|l|}{ Rhythm } \\
\hline Sinus & $11(100 \%)$ & $10(100 \%)$ & $11(100 \%)$ & $10(100 \%)$ & $5(100 \%)$ \\
\hline \multicolumn{6}{|l|}{ Surgery } \\
\hline CABG & $7(64 \%)$ & $4(40 \%)$ & $7(64 \%)$ & $5(50 \%)$ & $1(20 \%)$ \\
\hline AVR & $4(36 \%)$ & $5(50 \%)$ & $0(0 \%)$ & $5(50 \%)$ & $4(80 \%)$ \\
\hline $\mathrm{CABG}+\mathrm{AVR}$ & $0(0 \%)$ & $1(10 \%)$ & $4(36 \%)$ & $0(0 \%)$ & $0(0 \%)$ \\
\hline \multicolumn{6}{|l|}{ Medications } \\
\hline$\beta$-blocker & $8(73 \%)$ & $4(40 \%)$ & $7(64 \%)$ & $2(20 \%)$ & $1(20 \%)$ \\
\hline ACE inhibitor & $5(45 \%)$ & $5(50 \%)$ & $5(45 \%)$ & $3(30 \%)$ & $1(20 \%)$ \\
\hline Calcium channel blocker & $2(18 \%)$ & $0(0 \%)$ & $1(9 \%)$ & $1(10 \%)$ & $1(20 \%)$ \\
\hline Nitrate & $2(18 \%)$ & $2(20 \%)$ & $1(9 \%)$ & $1(10 \%)$ & $1(20 \%)$ \\
\hline Statin & $8(73 \%)$ & $2(20 \%)$ & $7(64 \%)$ & $5(50 \%)$ & $3(60 \%)$ \\
\hline MRA & $1(9 \%)$ & $1(10 \%)$ & $0(0 \%)$ & $0(0 \%)$ & $0(0 \%)$ \\
\hline Diuretic & $2(18 \%)$ & $1(10 \%)$ & $1(9 \%)$ & $0(0 \%)$ & $0(0 \%)$ \\
\hline Anti-arrhythmic & $0(0 \%)$ & $0(0 \%)$ & $0(0 \%)$ & $0(0 \%)$ & $0(0 \%)$ \\
\hline \multicolumn{6}{|l|}{ Trabecular dimensions } \\
\hline Length (mm) & 4.31 & 5.16 & 5.05 & 3.86 & 4.6 \\
\hline Diameter (mm) & 0.97 & 1.01 & 1.09 & 1.18 & 0.89 \\
\hline
\end{tabular}

LV, left ventricle; eGFR, estimated glomerular filtration rate; CABG, coronary artery bypass graft surgery; AVR, aortic valve replacement; ACE, angiotensin converting enzmye; MRA, mineralocorticoid receptor antagonist

*Data expressed as number $(\%)$ or mean

$\mathrm{pH} 7.4 \pm 0.5$ [5]. The muscle was electrically paced at $1 \mathrm{~Hz}$ and stretched until the maximum force of contraction (the peak of the Frank-Starling curve) was achieved. The muscle was subsequently allowed to stabilise for $90 \mathrm{~min}$ before being subjected to $60 \mathrm{~min}$ of hypoxia by superfusion with equiosmolar, glucose-free hypoxic modified Tyrode's buffer $\left(95 \% \mathrm{~N}_{2} / 5 \% \mathrm{CO}_{2}\right), \mathrm{pH} 7.4 \pm 0.5$ and electrical stimulation at $3 \mathrm{~Hz}$. The muscle was reoxygenated for $60 \mathrm{~min}$ with normoxic buffer and $1 \mathrm{~Hz}$ stimulation, to simulate reperfusion. Hypoxic preconditioning, consisting of $4.5 \mathrm{~min}$ hypoxia and pacing at $3 \mathrm{~Hz}$ followed by 6 min reoxygenation and pacing at $1 \mathrm{~Hz}$, was applied immediately prior to the index hypoxic period as a positive cardioprotective control [5]. SDF-1 $\alpha(25 \mathrm{ng} / \mathrm{ml})$, AMD3100 $(10 \mu \mathrm{g} / \mathrm{ml})$ or saline vehicle were administered for $30 \mathrm{~min}$ and $40 \mathrm{~min}$ respectively prior to index hypoxia, concentrations that were based on previous publications [4, 5].

\section{Immunohistochemistry}

In a separate group of experiments, isolated human atrial trabeculae were frozen and mounted in OCT before being cut into $5 \mu \mathrm{m}$ sections at $-20^{\circ} \mathrm{C}$ in a microtome-cryostat and transferred to slides. Sections were fixed with HistoChoice (Sigma-Aldrich, UK) for $20 \mathrm{~min}$ at room temperature and washed with PBS, before blocking with $5 \% \mathrm{BSA} / \mathrm{PBS}$ for 60 min. Immunofluorescent co-staining of CXCR4 and cardiomyocytes was performed using rabbit monoclonal anti-CXCR4 (ab124824) and mouse anti-cardiac troponin T (ab8295) from Abcam (Gillingham, UK). Anti-rabbit Alexa Fluor 488 and anti-mouse Alexa Fluor 555 secondary antibodies were purchased from Abcam. Cardiomyocyte co-stained samples were incubated in anti-CXCR4 and anti-cardiac troponin T, diluted in 1\% BSA/PBS 1:100 and 1:10 respectively, overnight at $4{ }^{\circ} \mathrm{C}$. Following washing and incubation with the appropriate secondary antibody diluted 1:400 in the same buffer for $60 \mathrm{~min}$ at room temperature, samples were washed again and coverslips mounted using fluorescence mounting medium (Dako, Ely, UK). $0.1 \mu \mathrm{g} / \mathrm{ml}$ Hoechst 33,258 nuclear stain (Life Technologies, Paisley, UK) was added with the secondary antibodies to all sections. Preparation of control sections was identical and they were incubated either with $1 \%$ BSA/PBS only (unstained control) or with the relevant secondary antibody in the absence of any primary antibody. After drying, Alexa 488 and Alexa 555 fluorescence was 
imaged using a $40 \times$ oil immersion objective, by sequential scanning using the $488 \mathrm{~nm}$ and $543 \mathrm{~nm}$ lines of a Leica SP5 confocal microscope and collecting emitted light at 500$530 \mathrm{~nm}$ and 580-650 nm respectively. Control experiments were performed to confirm the absence of fluorescence bleedthrough or non-specific staining with secondary antibodies alone.

\section{Statistics}

The final force of contraction in the human atrial trabeculae hypoxia-reoxygenation experiments was expressed as a percentage of baseline contractility to give recovery of function. Values are expressed as mean \pm SEM. Comparisons between more than 2 groups were made using 1-way analysis of variance (ANOVA). Fisher's protected least significant difference post hoc test was used for between-group comparisons. Differences were considered statistically significant when $P<0.05$.

\section{Results}

In control trabeculae, the mean recovery of function after hypoxia and reoxygenation was $27 \pm 2 \%$ [1]. Recovery of
Fig. 1 The SDF- $1 \alpha$-CXCR 4 axis protects human myocardium from hypoxia-reoxygenation injury: a Recovery of contractile function during simulated ischaemia and reperfusion applied to isolated human atrial trabeculae is improved by pre-treatment with exogenous SDF- $1 \alpha$ to a level similar to that conferred by hypoxic preconditioning. $\mathrm{N}=11$ atrial trabeculae in the control and SDF-1 $\alpha$ pre-treatment groups, 10 in the hypoxic preconditioning and AMD $3100+$ SDF- $1 \alpha$ pretreatment groups, and 5 in the AMD3100 pre-treatment group $*$ SDF- $1 \alpha$ vs. control, $\uparrow$ AMD + SDF- $1 \alpha$ vs. SDF- $1 \alpha(* P<0.05$, $* * P<0.005, * * * P<0.001) . \mathbf{b}$, Immunofluorescent staining of isolated human atrial trabeculae demonstrating the distribution of CXCR4 (green) in relation to cardiomyocytes (red). c, Immunofluorescent staining using secondary antibody in the absence of primary antibody. Representative images from $\mathrm{N}=2$ independent experiments, $50 \mu \mathrm{m}$ scale bar a

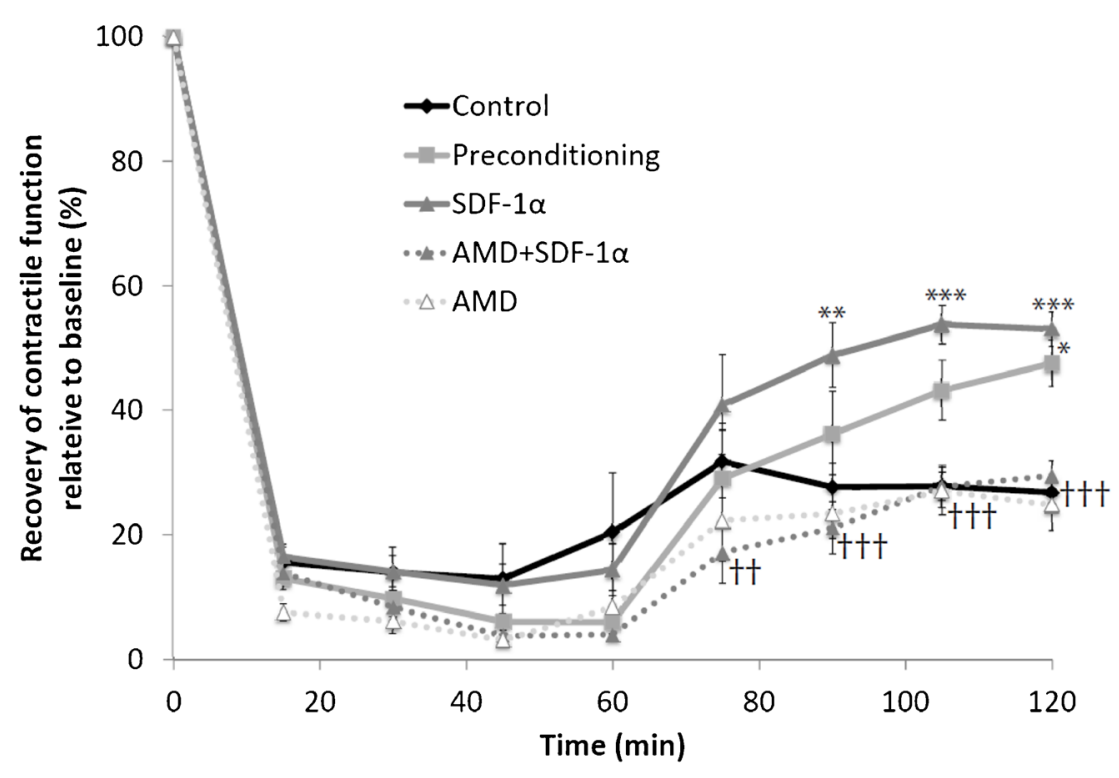

Hypoxia Reoxygenation
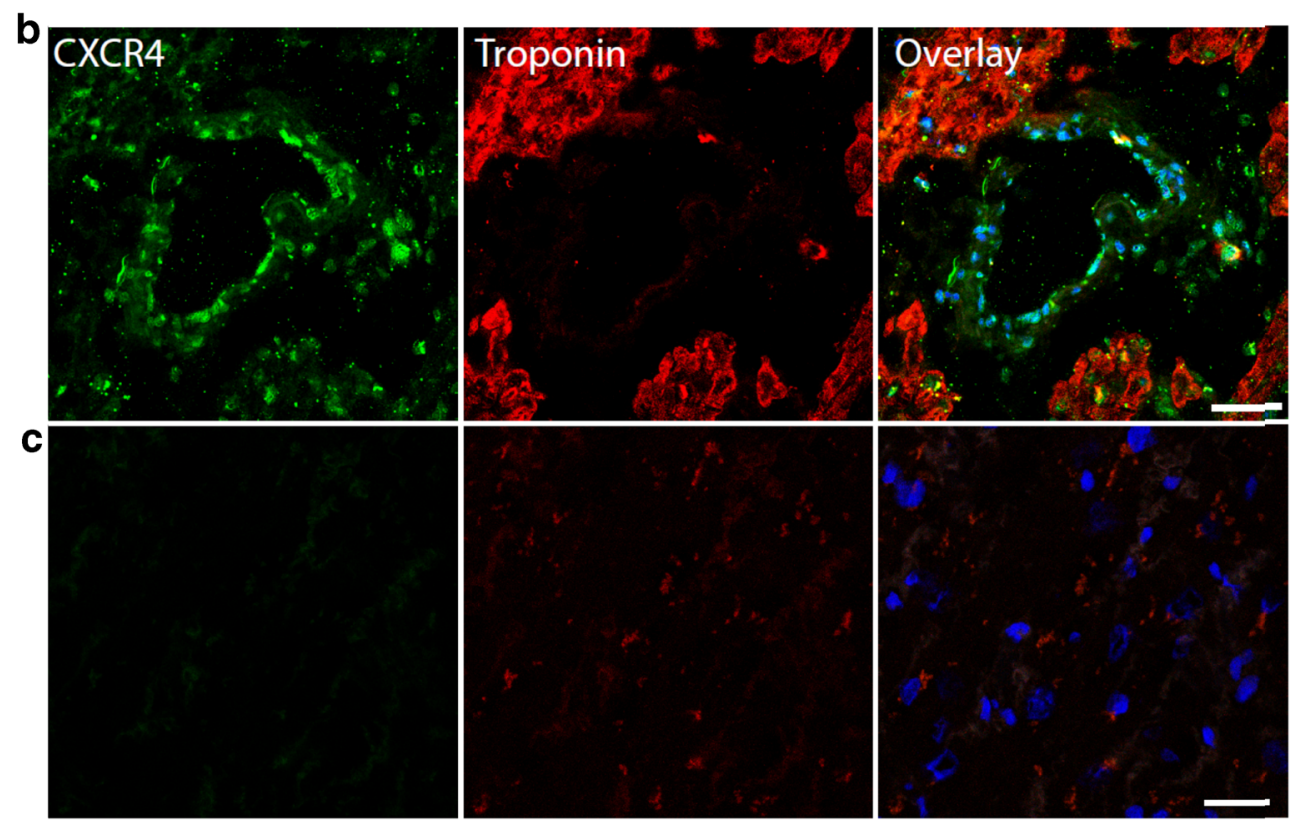
function in samples pre-treated with SDF- $1 \alpha$ was significantly increased ( $53 \pm 3 \%, P<0.05$ vs. control, Fig. 1$)$, which was similar to that in control trabeculae subjected to hypoxic preconditioning ( $48 \pm 4 \%, P<0.05$ vs. control).

The role of signalling via CXCR4 was investigated by pretreating trabeculae with the specific CXCR4 inhibitor, AMD3100, which abrogated the protective effect of SDF-1 $(30 \pm 2 \%, P<0.05$ vs. SDF- $1 \alpha$ alone). AMD3100 alone had no effect on functional recovery $(25 \pm 4 \%)$. Furthermore, immunofluorescent staining confirmed the presence of CXCR4 receptors on cardiomyocytes in human atrial trabeculae (Fig. 1).

\section{Discussion}

SDF- $1 \alpha$ is a small CXC chemokine that is expressed by several organs and tissues, including endothelial cells and cardiomyocytes in the heart [6]. Its cognate receptors CXCR4 and CXCR7 are similarly present in a range of tissues, including cardiomyocytes. The SDF-1 $\alpha /$ CXCR 4 axis has garnered considerable interest due to its role in stem cell homing, angiogenesis and ventricular remodelling after myocardial infarction, and has been used to target stem cells to ischaemic tissue, thereby improving LV dimensions and function [7].

We and others have previously demonstrated a cardioprotective role for SDF- $1 \alpha$ on both infarct size in isolated perfused rat hearts and recovery of function in isolated rat papillary muscle $[5,8]$. Both of these beneficial effects were abolished by AMD3100, all of which evidences a cardioprotective role for the SDF-1 $\alpha / \mathrm{CXCR} 4$ axis. Elsewhere, the application of exogenous SDF-1 has been shown to reduce apoptosis in isolated cardiomyocytes and SDF-1 infused into the murine LV cavity in vivo produced significantly smaller infarct sizes after IRI, both effects that were abrogated by AMD3100 [9].

This ex vivo functional model of hypoxia and reoxygenation translates the aforementioned findings to human myocardium for the first time, in the native milieu of the functional heart. This study confirms [1] the ability of exogenous SDF$1 \alpha$ to protect human atrial trabeculae from the detrimental effects of simulated IRI; [2] the role of CXCR4 in this mechanism, as evidenced by attenuating the benefits of SDF- $1 \alpha$ using the specific receptor blocker AMD3100; and [3] the presence and distribution of CXCR4 in human adult cardiomyocytes and endothelial cells.

There is evidence that the cardioprotective utility of SDF$1 \alpha /$ CXCR 4 may be conferred by activating intracellular prosurvival kinases, although the specific mechanism remains unknown [5]. However, it is thought to converge on the mitochondrial permeability transition pore (mPTP) and effect protection by delaying its opening and consequent necrotic cell death [10]. The exact mechanism of protection afforded by SDF-1 $\alpha /$ CXCR 4 should be the focus of further investigation in both basic and clinical studies.

In summary, our findings support the hypothesis that exogenous SDF- $1 \alpha$ is a preconditioning mimetic, herein shown to exert acute protection against the deleterious effects of hypoxia and reoxygenation and that this protection, in the isolated human atrial trabeculae, occurs via the CXCR4 receptor.

Acknowledgements Dr. Daniel Bromage is an MRC Clinical Research Training Fellow. This work was undertaken at UCLH/UCL who received a proportion of funding from the Department of Health's NIHR Biomedical Research Centres funding scheme of which DM Yellon is a Senior Investigator.

Open Access This article is distributed under the terms of the Creative Commons Attribution 4.0 International License (http:// creativecommons.org/licenses/by/4.0/), which permits unrestricted use, distribution, and reproduction in any medium, provided you give appropriate credit to the original author(s) and the source, provide a link to the Creative Commons license, and indicate if changes were made.

\section{References}

1. Gibson CM. NRMI and current treatment patterns for ST-elevation myocardial infarction. Am Heart J. 2004;148:S29-33.

2. Keeley EC, Boura JA, Grines CL. Primary angioplasty versus intravenous thrombolytic therapy for acute myocardial infarction: a quantitative review of 23 randomised trials. Lancet. 2003;361:1320.

3. Pedersen F, Butrymovich V, Kelbaek H, et al. Short- and long-term cause of death in patients treated with primary PCI for STEMI. J Am Coll Cardiol. 2014;64:2101-8.

4. Bromage DI, Davidson SM, Yellon DM. Stromal derived factor 1alpha: a chemokine that delivers a two-pronged defence of the myocardium. Pharmacol Ther. 2014;143:305-15.

5. Davidson SM, Selvaraj $\mathrm{P}, \mathrm{He} \mathrm{D}$, et al. Remote ischaemic preconditioning involves signalling through the SDF-1alpha/CXCR4 signalling axis. Basic Res Cardiol. 2013;108:377.

6. Zaruba MM, Franz WM. Role of the SDF-1-CXCR4 axis in stem cell-based therapies for ischemic cardiomyopathy. Expert Opin Biol Ther. 2010;10:321-35.

7. Penn MS, Pastore J, Miller T, Aras R. SDF-1 in myocardial repair Gene Ther. 2012;19:583-7.

8. Huang C, Gu H, Zhang W, Manukyan MC, Shou W, Wang M. SDF-1/CXCR4 mediates acute protection of cardiac function through myocardial STAT3 signaling following global ischemia/ reperfusion injury. AMERICAN J Physiol Heart Circ Physiol. 2011;301:H1496-505.

9. $\mathrm{Hu} \mathrm{X}, \mathrm{Dai} \mathrm{S}, \mathrm{Wu}$ WJ, et al. Stromal cell derived factor-1 alpha confers protection against myocardial ischemia/reperfusion injury: role of the cardiac stromal cell derived factor- 1 alpha CXCR 4 axis. Circ. 2007;116:654-63.

10. Davidson SM, Hausenloy D, Duchen MR, Yellon DM. Signalling via the reperfusion injury signalling kinase (RISK) pathway links closure of the mitochondrial permeability transition pore to cardioprotection. Int J Biochem Cell Biol. 2006;38:414-9. 